\title{
Políticas públicas e a garantia da prestação de informações ambientais no Estado do Paraná ${ }^{1}$
}

\author{
Pedro Junior da SILVA ${ }^{2}$ \\ Universidade Federal do Paraná, Curitiba, PR \\ Miguel Luiz CONTANI ${ }^{3}$ \\ Universidade Estadual de Londrina, Londrina, PR
}

\section{Resumo}

Este artigo avalia as políticas públicas e os instrumentos jurídicos que garantem a prestação de informações ambientais no Estado do Paraná. São analisadas as legislações em âmbito internacional, nacional e estadual relacionadas com a obrigatoriedade de os órgãos públicos divulgarem as informações ambientais de forma eficiente, correta e clara à população; os problemas encontrados nos órgãos públicos ambientais (Sema/Iap); a relação da mediação da comunicação entre a mídia e sociedade civil. Finaliza-se com algumas reflexões que podem contribuir para a efetivação do que é proposto nos ordenamentos jurídicos e na construção de uma sociedade ambientalmente responsável e democrática.

Palavras-Chave: Informação Ambiental; Políticas Públicas; Participação Popular.

\begin{abstract}
This paper is aimed at appraising public policies and juridical tools available to ensure information sharing on environmental issues in the State of Paraná. Local, national and international laws are overviewed, and the obligation of public offices to divulge environmental information, effectively, dependably and clearly to the public is analyzed; so are the problems found among public environmental authorities (Sema/Iap) and the relation of media as communicative mediator towards the civil society. In conclusion, reflections are presented with the purpose of contributing to the implementation of the proposed juridical order and in building an environmentally responsible and democratic society.
\end{abstract}

Keywords: Environmental Information; Public Policies; People's Participation.

\footnotetext{
${ }^{1}$ Trabalho apresentado à segunda edição da Revista Ação Midiática - Estudos em Comunicação, Sociedade e Cultura, publicação ligada ao Programa de Pós-Graduação em Comunicação e Sociedade, da Universidade Federal do Paraná.

${ }^{2}$ Graduado em Direito pela Universidade Federal do Mato Grosso, doutorando do Programa de Pós-Graduação em Meio Ambiente e Desenvolvimento - UFPR, email: t.junior.silva@uol.com.br.

${ }^{3}$ Doutor em Comunicação e Semiótica pela PUC-SP, docente da Universidade Estadual de Londrina, email: contani@sercomtel.com.br.
} 


\section{Introdução}

Em todas as sociedades, em todas as épocas, há a produção e o intercâmbio de informações e de conteúdo. Desde as mais antigas formas de comunicação gestual e de uso da linguagem até os mais recentes desenvolvimentos na tecnologia computacional, a produção, o armazenamento e a circulação de informação e conteúdo têm sido aspectos centrais. Com a crescente degradação ambiental, houve a criação de diversas legislações nacionais e internacionais que constituem as regras primordiais e tentam reger o comportamento da sociedade, principalmente, com o objetivo de propiciar o desenvolvimento equilibrado da vida em todas as suas formas; em tese, são atenções voltadas e direcionadas para implementar as políticas públicas ambientais.

No âmbito internacional, a preocupação com essa problemática surgiu com as conferências da Organização das Nações Unidas (ONU). De 1972 até os dias atuais, ocorreram três daqueles eventos mundiais - a Conferência de Estocolmo (1972), a Conferência do Rio de Janeiro (1992) e a Rio + 10, em Johanesburgo (2002) - que foram decisivos para que a temática ambiental, como desenvolvimento sustentável, mudanças climáticas, biodiversidade etc., assumissem centralidade na agenda dos meios de comunicação.

Todavia, mesmo com a "avalanche" de leis ambientais criadas com o intuito de proteger o meio ambiente, abrangendo os elementos bióticos (seres vivos) e abióticos (seres não-vivos) para permitir a vida em todas as suas formas, muito pouco se conseguiu avançar em temos de consciência e cidadania ambiental nessas últimas quatro décadas. Falta ainda conhecimento e há pouca circulação de informação para efetivar tais legislações.

Dessa forma, a divulgação da informação ambiental, de mãos dadas com as práticas de mídia, constitui o objeto deste artigo, que busca discutir uma noção geral do conceito de informação ambiental, apontar os instrumentos jurídicos em nível internacional, nacional e regional, analisar a conjuntura dos principais institutos paranaenses. Para atingir esse objetivo, efetuou-se um levantamento das legislações ambientais e realizaram-se entrevistas in loco com os funcionários dos órgãos públicos que, no estado, cuidam diretamente do assunto: Secretaria de Estado do Meio Ambiente e Recursos Hídricos - Sema e Instituto Ambiental do Paraná - Iap

\section{Informação ambiental nos instrumentos jurídicos em âmbito internacional e nacional}


O princípio do direito à informação a partir de seu fundamento nos ordenamentos jurídicos como na Declaração Universal dos Direitos Humanos de 1948 manifestou, em seu art. 19, que "toda pessoa tem direito à liberdade de opinião e expressão; este direito inclui a liberdade de, sem interferências, ter opiniões e de procurar receber e transmitir informações $\mathrm{e}$ ideias por quaisquer meios $\mathrm{e}$ independentemente de fronteiras".

Esse ordenamento e todos os tratados normativos nele inspirados, preparam o terreno para o surgimento desse direito subjetivo no mundo jurídico - o direito à informação. Tais instrumentos jurídicos - documentos escritos que servem para fazer constarem fato ou convênio de que derivam consequências jurídicas - consideram a informação como garantia à vida de todos no planeta, e essencial na proteção do meio ambiente e da saúde coletiva.

Neste sentido, o direito à informação está contemplado no art. $5^{\circ}$ da Constituição Federal (CF) do Brasil de 1988, inserto no Capítulo dos direitos e deveres individuais e coletivos, inciso XIV, art. 5', que estabelece: "é assegurado a todos o acesso à informação e resguardado o sigilo da fonte, quando necessário ao exercício profissional". Primeiramente, cabe dizer que a informação é assegurada a todas as pessoas, independentemente de sua profissão. Por outro lado, a última parte do inciso assegura que os profissionais ligados à mídia (jornalistas, radialistas, e outros produtores) possam guardar sigilo de suas fontes, caso seja realmente relevante para o exercício profissional.

Ainda o art. $5^{\circ}$ da CF, em seu inciso XXXIII, considera que: "Todos têm direito a receber dos órgãos públicos informações de seu interesse particular, ou de interesse coletivo ou geral, que serão prestadas no prazo da lei, sob pena de responsabilidade, ressalvadas aquelas cujo sigilo seja imprescindível à segurança da sociedade e do Estado”. Dessa forma, há, nessa determinação, a consagração do status civitatis, pois o direito à informação é fundamentado no interesse particular do cidadão ou no interesse coletivo de quem quer ser informado.

Em relação ao direito à informação ambiental, mesmo durante o período de governo militar, quando ainda havia a censura de informações, criou-se a Política Nacional do Meio Ambiente (PNMA), Lei n 6.938/1981, que visa, em seu art. 4º, inciso V, "à difusão de tecnologias de manejo do meio ambiente, à divulgação de dados e informações ambientais e à formação de uma consciência pública sobre a necessidade de preservação da qualidade ambiental e do equilíbrio ecológico".

A PNMA também foi importante porque inseriu, pela primeira vez, a noção de meio ambiente como patrimônio público - "o conjunto de condições, leis, influências e 
interações de ordem física, química e biológica, que permite, abriga e rege a vida em todas as suas formas" (art. $\left.3^{\circ}, \mathrm{I}\right)$-, além de obrigar à publicação e transparência do licenciamento ambiental (art. 10).

Ademais, escolheu-se a obrigatoriedade dos meios de comunicação impressos (jornal oficial, jornais locais de grande circulação) para veicular os dados sobre o licenciamento ambiental, facilitando o acesso à informação para sociedade. No início da década de 1980, essa escolha da divulgação impressa foi a mais conveniente, pois na época a comunicação eletrônica não estava ainda tão difundida.

Com a promulgação da Constituição Federal em 1988, o direito à informação ambiental estabeleceu uma interdependência com a educação ambiental. Esta última é uma consequência necessária do direito de ser informado, previsto nos arts. 220 e 221 da CF. Todavia, o art. 220 engloba não só o direito à informação, mas também o direito a ser informado, que se mostra como um direito difuso, ou seja, coletivo.

Uma das formas de levar à prática esses dispositivos constitucionais é assegurar a participação de todos os cidadãos interessados. Nesse sentido, um dos documentos aprovados pela Conferência das Nações Unidas sobre o Meio Ambiente e Desenvolvimento (Rio-92), a Carta da Terra ou Declaração do Rio, explicita o dever dos Estados de tornar as informações ambientais acessíveis a todos:

[...] Cada indivíduo deve ter acesso adequado a informações relativas ao meio ambiente de que disponham as autoridades públicas, inclusive informações sobre materiais e atividades perigosas em suas comunidades, bem como a oportunidade de participar em processos de tomadas de decisões. Os Estados devem facilitar e estimular a conscientização e a participação pública, colocando a informação à disposição de todos [...] (CARTA DA TERRA, PRINCÍPIO 10).

A Agenda $21^{4}$, outro documento aprovado na Rio-92, na introdução do Capítulo 40, Seção IV, cita os meios de pôr em prática aquele programa: "No desenvolvimento sustentável, cada pessoa é usuário e provedor de informação, considerada em sentido amplo, o que inclui dados, informações e experiências e conhecimentos adequadamente apresentados".

Para garantir a efetivação do princípio da informação ambiental, o governo federal sancionou a Lei $\mathrm{n}^{\circ} 10.650$, de 16 de abril de 2003, que trata do acesso público às informações ambientais, do fornecimento dessas informações e da obrigatoriedade da publicação de determinadas matérias no Diário Oficial. O art. $1^{\circ}$ dessa Lei comenta que ela "dispõe sobre o acesso público aos dados e informações ambientais existentes nos

\footnotetext{
4 Agenda 21 é um programa de ação a ser adotado pelos governos, instituições da ONU, agências de desenvolvimento e setores independentes, baseado em um documento de 40 capítulos, que constitui a mais ousada e abrangente tentativa já realizada de promover, em escala planetária, um novo padrão de desenvolvimento, conciliando métodos de proteção ambiental, justiça social e eficiência econômica.
} 
órgãos e entidades integrantes do Sistema Nacional do Meio Ambiente (Sisnama)", instituído pela Política Nacional do Meio Ambiente.

Aparentemente, a Lei $\mathrm{n}^{\mathrm{o}} 10.650$ é bem intencionada; contudo, Machado (2006, p. 205) considerou-a "incompleta", pois se autolimita ao conceder acesso público aos dados e informações ambientais existentes. De acordo com o autor, para que princípio da informação ambiental possa ser implementado é necessário que

O Poder Público deve informar sobre as matérias que lhe compete controlar ou fiscalizar. Não pode desculpar-se por não informar alegando que não detém as informações. A admissão dessa desculpa significaria a concordância com o descumprimento da obrigação constitucional, pois a omissão governamental se tornaria praxe. Além do mais, abre-se uma porta para a conivência do Poder Público com os agressores da natureza e com os poluidores, estimulando-se os órgãos públicos a não saber, para não informar (MACHADO, 2006, p. 205).

Todos esses instrumentos jurídicos corroboram a importância do acesso e a divulgação da informação ambiental. Há, no entanto, outros dispositivos relevantes que também comentam tal obrigatoriedade. Entre eles podem-se citar: a Lei $n^{\circ}$ 7.802/1989 (Lei de Registro de Agrotóxicos), a Lei no 9.433/1997 (Lei de Política Nacional de Recursos Hídricos), a Lei $n^{\circ} 10.257 / 2001$, (Estatuto da Cidade, art. 40, $\S 4^{\text {o }}$, incs. II e III), a Lei $n^{\circ} 11.284 / 2006$ (Lei de Gestão de Florestas, art. $2^{\circ}$, incs. V e VII), dentre outras.

\section{A redemocratização e a Constituição Federal de 1988: um enfoque socioambiental}

\section{da informação}

Com o fim da ditadura militar (1964-1985), a última eleição indireta do presidente da república em 15 de janeiro de 1985 e a instalação, em 1988, da Assembleia Nacional Constituinte, a participação da sociedade ganha novos contornos. Para Silva (1990), ao longo dos últimos anos da ditadura militar, havia-se desenvolvido um amplo movimento de solidariedade profissional de camadas sociais que ansiavam por uma democracia concebida como a ampliação da participação do indivíduo na vida pública. Assim, a cidadania vem a ser um "produto de uma relação entre indivíduos e Estado; uma relação de poder composta de pressões e contrapressões, produzindo imagens simbólicas dinâmicas de auto-reconhecimento dos grupos sociais e dos seus projetos" (SILVA, 1990, p. 390).

Tais expectativas desembocaram diretamente na Assembleia Constituinte, e pela primeira vez na história do Brasil, ela atendeu às pressões das novas formas de representação, como emendas populares e o reconhecimento das inúmeras campanhas a 
favor dos trabalhadores, de minorias raciais e sexuais, da mulher, da criança e do jovem, dos movimentos ambientalistas e outros.

Nesse sentido, a democracia deliberativa

é a concepção de democracia que trata todos os indivíduos como agentes autônomos, capazes de formar juízos razoáveis através da assimilação de informações e diferentes pontos de vista, e que institucionaliza uma variedade de mecanismos para incorporar os juízos individuais num processo coletivo de tomada de decisão [...] O processo de decisão é necessariamente aberto. Quanto mais informação estiver disponível e mais os indivíduos puderem considerar os argumentos e as reivindicações dos outros, tanto mais poderão gradualmente modificar seus pontos vistas originais (THOMPSON, 2009, p. 220).

Pelo menos em tese, esse foi o ideal durante a construção da Constituição Federal de 1988, que lhe valeu o epíteto de "Constituição Cidadã", por conta da incorporação de uma série de direitos civis e sociais. Em relação à conduta dos cidadãos em tomar parte em alguma coisa na sociedade, ou de agir em conjunto, a CF considerou importante e necessário o princípio da participação comunitária. Com o acesso às informações ambientais, por exemplo, em vez da submissão às decisões prontas, permite-se, ao cidadão, participar do debate, da formulação, da execução e da fiscalização das políticas ambientais, em contribuição à democracia deliberativa (OLIVEIRA, 2010).

A CF, em seu art. 225, caput, expressou a defesa do meio ambiente, a atuação presente do Estado e da sociedade civil ao impor, à coletividade e ao setor público, tais deveres: "Todos têm direito ao meio ambiente ecologicamente equilibrado, bem de uso comum do povo e essencial à sadia qualidade de vida, impondo-se ao Poder Público e à coletividade o dever de defendê-lo e preservá-lo para as presentes e futuras gerações".

Conforme Fiorillo (2002), é oportuno considerar que o resultado dessa omissão participativa é um prejuízo a ser suportado pela própria coletividade, tendo em vista que o direito ao meio ambiente tem natureza difusa, ou seja, seus riscos não apresentam limites precisos. Ademais, o fato de a administração desse bem ficar sob a custódia do Poder Público não elimina o dever de o povo atuar na conservação e preservação do meio ambiente.

Para o autor, o princípio da participação constitui ainda um dos elementos do "Estado Social de Direito [um dos princípios da Conferência de Estocolmo], e que também poderia ser chamado de Estado Ambiental de Direito, visto que todos os direitos sociais são a estrutura essencial de uma saudável qualidade de vida, que é um dos pontos cardeais da tutela ambiental" (FIORILLO, 2002, p. 39). 
A questão ambiental acabou dominando a agenda atual e, em torno dela, muitas tensões e muitas possibilidades estão agrupadas. Nessa perspectiva, alguns movimentos, como a Rede Brasileira de Justiça Ambiental, por exemplo, buscam alternativas aos modelos excludentes de participação popular e, como questiona Galeano (2006, p. 149), a sociedade contemporânea está "a caminho de uma sociedade da incomunicação?", pois como nunca a tecnologia das comunicações foi tão aperfeiçoada e, no entanto, o mundo se parece cada vez mais habitando um "reino de mudos".

Um dos grandes obstáculos para efetivar a ação em conjunto da população e a preservação ambiental na "sociedade da informação", é que a informação é "assunto de engenheiro", pois o que importa é o canal - meio físico onde a mensagem se propaga e a informação fica separada da cultura e da memória. Nesse esquema mecânico no atual processo de informação, como no caso da divulgação ambiental, sua representação é linear e difunde-se de cima para abaixo, do centro para as periferias.

Seria mais pertinente e adequado, que houvesse uma comunicação entre poder público e sociedade, no sentido de envolvimento entre quem comunica e quem recebe a comunicação, e a mensagem pudesse se estabelecer em ciclo de "bem comum" entre o emissor-receptor. Hoje o que se percebe é que nesse modelo de divulgação da informação, nem sempre há esse relacionamento, pois o conteúdo da mensagem pode estar armazenado, bastando que o interessado a procure e acesse.

O objetivo da comunicação é tornar-se uma possibilidade de libertação e favorecer a emergência de condições objetivas para que o ser humano possa construir uma relação com o meio ambiente de maneira mais compreensiva dentro da sua realidade.

\section{A divulgação da informação ambiental no Estado do Paraná}

A consolidação do modelo de gestão democrático exige que as informações produzidas sejam sistematizadas e colocadas à disposição de toda a sociedade. Esse é um dos mais importantes pressupostos para que haja a participação comunitária na gestão ambiental, uma vez que permite, aos cidadãos, tomar consciência dos riscos a que estão submetidos e terem capacidade de articular seus interesses dentro dos processos de deliberação e gestão ambiental. Além disso, a informação é requisito para que a sociedade possa monitorar e avaliar tanto a qualidade do meio ambiente quanto a efetividade das estratégias de gestão implantadas.

Pela total relevância da informação ambiental, é preciso responder a algumas questões em relação a essa obrigatoriedade e responsabilidade no Paraná. Qual órgão estadual é responsável pela produção das informações ambientais no Estado? Há leis 
estaduais que obrigam o governo a fazê-lo? Como reverter o quadro atual da ineficácia na divulgação das informações ambientais no Estado?

A Constituição do Paraná de 1989, em seu art. 206, estabelece que: “O Estado, dando prioridade à cultura regional, estimulará a manifestação do pensamento, a criação, a expressão e a informação, sob qualquer forma, processo ou veículo, as quais não sofrerão restrição, observados os princípios da Constituição Federal". Essa determinação considera que o Poder Público estadual deve agir com a maior transparência possível, visível a qualquer hora e em qualquer momento, "e não visa mostrar só o que é bom e esconder o que é mau ou sofrível” (MACHADO, 2006, p. 62).

Em relação às questões ambientais, a determinação da Constituição Estadual é semelhante à CF/1988, e determina que: "Todos têm direito ao meio ambiente ecologicamente equilibrado, bem de uso comum e essencial à sadia qualidade de vida, impondo-se ao Estado, aos Municípios e à coletividade o dever de defendê-lo e preservá-lo para as gerações presentes e futuras, garantindo-se a proteção dos ecossistemas e o uso racional dos recursos ambientais" (ART. 207, caput).

O mesmo art. 207, $\S 1^{\circ}$, incisos IX e X, afirma adicionalmente que: "Cabe ao Poder Público, na forma da lei, para assegurar a efetividade deste direito: informar à população sobre os níveis de poluição e situações de risco e desequilíbrio ecológico; promover a educação ambiental em todos os níveis de ensino e a conscientização pública para a preservação do meio ambiente".

Além da Constituição do Paraná, a Lei no 12.726/1999, trata da Política Estadual de Recursos Hídricos, e em seu art. 6, VI, cita o seguinte: "São instrumentos da Política Estadual de Recursos Hídricos: VI - o Sistema Estadual de Informações sobre Recursos Hídricos". Esse Sistema é coordenado pelo Conselho Estadual de Recursos Hídricos (Cerh), pertencente à Secretaria de Estado do Meio Ambiente e Recursos Hídricos.

Em relação à divulgação das informações ambientais, muitos dos objetivos daquele Sistema de Informações, tais como, "reunir, dar consistência e divulgar os dados e informações sobre a situação qualitativa e quantitativa dos Recursos Hídricos do Estado do Paraná, sem prejuízo de informações socioeconômicas relevantes para o seu gerenciamento" e "atualizar, permanentemente, as informações sobre disponibilidade e demanda de recursos hídricos e sobre ecossistemas aquáticos em todo o território do Estado", na maior parte das vezes, não estão sendo cumpridos, seja por falta de eficiência e rapidez na atualização, ou quiçá por razões políticas desconhecidas.

\section{Secretaria de Estado do Meio Ambiente e Recursos Hídricos - Sema}


A Sema é o órgão de primeiro nível hierárquico da administração estadual, de natureza substantiva, que tem por finalidade formular e executar as políticas de meio ambiente, de recursos hídricos, florestal, cartográfica, agrária-fundiária, de controle da erosão e de saneamento ambiental, além de coordenar o Sistema Estadual de Gestão Ambiental e dos Recursos Hídricos do Estado ${ }^{5}$.

O governo paranaense reconheceu, no ano de 2000, a necessidade de uma abordagem de governança socialmente inclusiva dentro da Sociedade da Informação. Um exemplo desse tipo de visão aplicada na prática é o da Sema: dentro de sua estrutura organizacional, os Conselhos (Meio Ambiente, Recursos Hídricos etc.), Assessorias (técnicas e jurídicas) e Coordenadorias (Mudanças Climáticas, Biodiversidade e Educação Ambiental) trabalham juntos para atingir o objetivo de disponibilizar o acesso às informações ambientais à população paranaense.

Em relação ao assessoramento técnico, a Sema possui a Assessoria de Comunicação que é o principal contato entre sociedade e serviços ambientais, além de realizar o trabalho para a divulgação dos resultados das ações promovidas. Dentre os vários objetivos ${ }^{6}$ que a Secretaria definiu, podem-se destacar a promoção, coordenação e execução da educação ambiental; e execução, coordenação para atualização e divulgação do Sistema de Informações Ambientais.

De forma mais institucional, a Assessoria de Comunicação divulga as informações ambientais para a sociedade principalmente por meios eletrônicos, procurando, dentro de suas limitações, focar no cidadão, mesmo com o aumento da quantidade de serviços e o decréscimo nos recursos humanos (são apenas três funcionários: dois jornalistas e um fotógrafo) para atender todo o Paraná. Esse problema do "sucateamento" dos recursos humanos no setor público estadual, e em geral no

\footnotetext{
${ }^{5}$ Disponível em: www.sema.pr.gov.br; acesso em 26 de julho de 2011.

${ }^{6} \mathrm{O}$ campo de atuação da Sema no Paraná compreende as seguintes atividades: estabelecer as diretrizes para ação governamental nas áreas de meio ambiente, de recursos hídricos, florestal, cartográfica, agrária-fundiária, de controle da erosão e de saneamento ambiental; promover, coordenar e executar a educação ambiental; promover a regularização fundiária e o reordenamento territorial, de forma a garantir a proteção dos recursos naturais e a manutenção da biodiversidade, contemplada sempre a função social da terra; estabelecer programas, em conjunto com o órgão responsável da União, para implantação de projetos de assentamentos de agricultores sem-terra no Estado, no âmbito federal através do Plano Nacional de Reforma Agrária e no âmbito estadual através do Plano Especial de Colonização; participar, em conjunto com os órgãos competentes das diferentes esferas de governo, da elaboração e execução do Plano Especial de Colonização e, do Plano Nacional de Reforma Agrária; promover, normatizar, coordenar e executar a cartografia do Estado, realizar atividades na área de sensoriamento remoto, bem como manter o acervo de seus produtos; executar e fazer executar todos os atos necessários à proteção, conservação e recuperação do meio ambiente; promover a execução, a coordenação, o controle, a atualização e a divulgação do Sistema de Informações Ambientais; promover a realização de estudos ambientais de caráter multi e interdisciplinar, de forma integrada; promover o desenvolvimento de métodos e padrões de avaliação da qualidade ambiental; promover o planejamento, a execução e o controle de projetos especiais e obras relativas ao meio ambiente; coordenar a proposição e a elaboração de políticas, normas, estratégias, programas e projetos relacionados à gestão de resíduos sólidos, recursos hídricos e atmosféricos, biodiversidade e florestas, contribuindo para com a definição e implementação da política ambiental do Estado (Disponível em: www.sema.pr.gov.br, acesso em 26 de julho de 2011).
} 
Brasil por inteiro, significa muitas vezes deixar de atender às demandas da população. Consequentemente, perde-se cada vez mais legitimidade, credibilidade e autoridade.

Essa Assessoria de Comunicação divulga as informações por meio de oito ferramentas: a página eletrônica da agência estado de notícias (www.aenoticias.pr.gov.br); o site institucional (www.sema.pr.gov.br); pelo e-mail oficial (comunicacaosocial@sema.pr.gov.br); atendimentos e prestação de serviço pelos telefones (DDD 41 3304-7797 / 3304-7854 / 3304-7796); pela rádio do governo; pela Televisão Educativa (E PARANÁ); pelas redes sociais, como o Facebook e Twitter (@ semapr); e pelo boletim eletrônico semanal, que são enviados para mais de 60 mil usuários.

\section{Instituto Ambiental do Paraná - Iap}

O Instituto Ambiental do Paraná é uma autarquia institucional criada pela Lei Estadual $\mathrm{n}^{\circ}$ 10.066, de 27 de julho de 1992. Como autarquia, o IAP é uma pessoa jurídica que dispõe de patrimônio próprio e realiza atividades típicas de Estado de forma descentralizada, como por exemplo, proteger, preservar, conservar, controlar e recuperar o meio ambiente, buscando melhor qualidade de vida e o desenvolvimento sustentável com a participação da sociedade.

Uma das atribuições ${ }^{7}$ do Iap é divulgar informações referentes às condições de balneabilidade das praias do litoral, costa oeste e região norte; fornecer os boletins da qualidade do ar na Região Metropolitana de Curitiba (RMC) e publicar os relatórios de impacto ambiental provenientes dos estudos de impacto ambiental (Eia/Rima).

Para exemplificar umas dessas atribuições, publicou-se o Relatório Anual da Qualidade do Ar na Região Metropolitana de Curitiba Ano 2010, que pautou o noticiário em veículos de comunicação, como o jornal Gazeta do Povo, de 17/08/2011, e divulgou que o ar da RMC esteve dentro dos padrões de qualidade estabelecidos pela

\footnotetext{
${ }^{7}$ São atribuições do Iap: cumprir a legislação ambiental, exercendo, o poder de polícia administrativa, controle, licenciamento e fiscalização; conceder licenciamento ambiental prévio para instalação, operação e ampliação de atividades poluidoras ou perturbadoras do meio ambiente; Licenciar empreendimentos florestais e autorizar desmates; estudar e propor normas, padrões e especificações de interesse para a proteção da qualidade ambiental; analisar e emitir pareceres em projetos, relatórios de impacto ambiental e de riscos; elaborar, executar e controlar planos e programas de proteção e preservação da biodiversidade e a integridade do patrimônio genético; participar da administração de parques e reservas de domínio dos municípios ou da União, mediante convênios; incentivar e assistir às prefeituras municipais no tocante à implementação de bosques, hortos e arborização urbana e repovoamento de lagos e rios; executar e fazer executar a recuperação florestal de áreas de preservação permanente degradadas e de unidades de conservação, diretamente ou através de convênios e consórcios; fiscalizar, orientar e controlar a recuperação de áreas degradadas por atividades econômicas de qualquer natureza; promover, coordenar e executar a educação ambiental formal e não formal; executar o monitoramento ambiental, em especial da quantidade e qualidade dos recursos hídricos superficiais e subterrâneos, do ar e do solo; controlar e fiscalizar os agrotóxicos e afins e produtos perigosos, quanto ao transporte e destinação final de resíduos, nos termos da legislação específica vigente; cadastrar os produtos agrotóxicos utilizados no Estado, quanto ao seu aspecto ambiental; definir a política florestal do estado, observados seus aspectos sócio-econômicos e ecológicos (Disponível em: www.iap.pr.gov.br, acesso em 26 de julho de 2011).
} 
legislação brasileira na maior parte de 2010. De acordo a pesquisa, a classificação permaneceu na condição "boa" em 95\% do tempo; "regular" em 4,8\%; e "inadequada" ou "má" em apenas $0,2 \%$ do período. O Instituto utiliza critério próprio (o Índice de Qualidade do Ar) para medir as condições do ar na RMC. Os padrões se baseiam na Resolução 03/90 do Conselho Nacional do Meio Ambiente.

O Iap, na maior parte das vezes, articula suas ações com a SEMA e, dessa forma, garante um bom fluxo de informações, para facilitar a colaboração entre esses órgãos ambientais. A ideia é permitir a elaboração e execução de políticas públicas comuns, por meio de parcerias formais e de projetos ambientais específicos, em que cada participante contribui com suas competências e recursos humanos, físicos, financeiros, gerenciais e operacionais. Um exemplo desse tipo de articulação é o projeto "Áreas Estratégias para a Conservação da Biodiversidade no Paraná”, com parceria entre Sema, Iap e o The Nature Conservancy (Estados Unidos).

Um dos grandes desafios do Iap, assim como o da Sema, é a necessidade de maior eficiência na divulgação das informações ambientais. Na Assessoria de Comunicação do Instituto, há somente uma jornalista, com cargo comissionado, para atender à grande demanda dos meios de comunicação e da população.

Nesse sentido, vale citar a crítica de Kassmayer (2011) sobre a causa da demora no julgamento dos processos do Iap, para quem "além da falta de funcionários, o órgão está sucateado. O Instituto tem várias funções, uma demanda cada vez maior, e um número de funcionários que corresponde a um terço do que tinha dez anos atrás." (KASSMAYER, p.2, 2011). O Iap tem hoje 582 funcionários em todo o Estado, trabalhando na fiscalização e na administração do órgão.

\section{A mídia e a mediação das informações ambientais no Paraná}

"Não podemos escapar à mídia. Ela está presente em todos os aspectos de nossa vida cotidiana" (SILVERSTONE, 2005, p. 9). Diante desse pressuposto, as comunicações de massa, como os jornais e a televisão, têm uma ampla influência sobre a experiência dos atores sociais e, consequentemente, sobre a opinião pública, não apenas por afetarem suas atitudes em modos específicos, mas por serem o meio de acesso ao conhecimento do qual dependem muitas atividades sociais, como o conhecimento das questões ambientais.

Nesse sentido, com a globalização, a mídia adquire importância crescente na organização e dinâmica da vida do indivíduo, do grupo, da classe, do povo ou sociedade (IANNI, 2002, p.132). Castells (1999, p.361) acrescenta que, "vivemos em um ambiente 
de mídia, e a maior parte de nossos estímulos simbólicos vem dos meios de comunicação". Para corroborar com esse pensamento, Beck afirma que

Os indivíduos não são diretamente ativos. Os protestos foram simbolicamente intermediados pela mídia. $\mathrm{O}$ homem foi remetido à política simbólica da mídia, algo que pode ser reconhecido particularmente no caráter abstrato e onipresente da destruição que está colocada diante da sociedade de risco. Os símbolos simplificados que tocam e sensibilizam os nervos culturais, adquirem um significado político decisivo. Estes símbolos precisam ser criados e ao mesmo tempo represados em meio ao fogo da emergência destes conflitos - tudo isto diante dos olhos televisivos da esfera pública, tomados por um misto de espanto e indignação (BECK, 1999, p. 131).

Nessa perspectiva, o debate político perdeu seu locus histórico nos últimos anos, o espaço público das ruas e praças, onde os cidadãos se reuniam para discutir suas idéias. Hoje, ele se dá quase integralmente por meio dos veículos de comunicação de massa, o que confere a esses órgãos de comunicação um considerável poder de convencimento. O que Bourdieu (1997, p.29) afirma sobre a televisão, pode ser estendido aos outros veículos de massa: "a televisão que se pretende um instrumento de registro torna-se um instrumento de criação da realidade. Caminha-se cada vez mais rumo a universos em que o mundo social é descrito/prescrito pela televisão, esta se tornou o árbitro do acesso à existência social e política".

$\mathrm{Na}$ divulgação dos riscos ambientais produzidos na modernidade, Beck (1999, p.79) observa que "as turbulências político-econômicas e culturais dos riscos mundiais só se tornam compreensíveis quando há o reconhecimento de que os perigos são discutidos na esfera pública". O autor ainda acrescenta,

O que mais chama a atenção nos conflitos provocados por estes riscos é o fato de que âmbitos de decisão antes despolitizados tornaram-se politizados em função da percepção pública dos riscos; e eles permanecem abertos à dúvida pública e ao debate. Na sociedade mundial globalizada são anunciados e discutidos publicamente durante a noite e objetos de discussão que já foram decididos a portas fechadas durante o dia, como por exemplo, decisões sobre investimentos, a composição química de produtos e medicamentos, programas de pesquisa científica, o desenvolvimento de novas tecnologias (BECK, 1999, p.176).

Para o grande público, essas informações só chegam pela mídia, que muitas vezes, ao discutir os assuntos da ordem do dia, não apresentam todos os lados da questão, fazendo com que os receptores das mensagens não desenvolvam uma perspectiva crítica e fiquem no status de leigos, querendo confiar, ou sabendo do risco da confiança.

Para realizar este estudo, algumas entrevistas foram realizadas com a finalidade de conhecer o trabalho realizado pelas assessorias de comunicação da Sema e do Iap. Os 
dados apresentados no gráfico 1 fundamentam a tese de que, na passagem dos problemas ambientais de condições para assunto, e depois para condicionantes da elaboração de políticas, a visibilidade na mídia é muito relevante. Pois sem a cobertura dos meios de comunicação, é pouco provável que problemas antigos entrem na área do discurso público ou venham a fazer parte do processo político.

Gráfico 1 - Origem das demandas de informações ambientais na Sema/Iap do Paraná

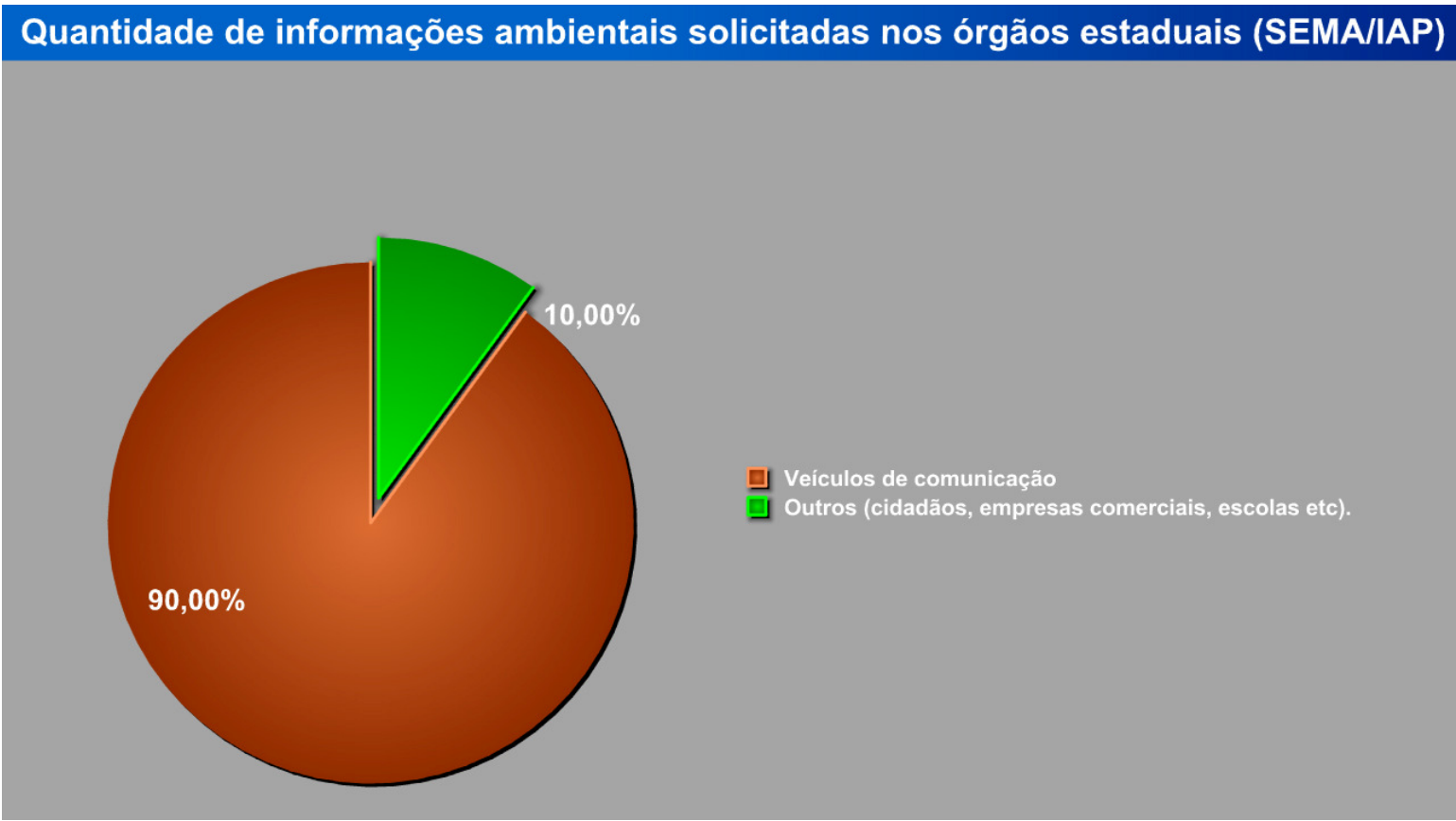

Fonte: Pesquisa realizada em 2011

De acordo com o gráfico, 90\% das solicitações sobre questões ambientais recebidas na Secretaria de Estado do Meio Ambiente e Recursos Hídricos e no Instituto Ambiental do Paraná, são dos veículos de comunicação (rádio, televisão, jornais impressos etc.) e apenas $10 \%$ de outros setores da sociedade civil (cidadãos, escolas, empresas privadas etc.). Isto mostra de fato que a maior parte das pessoas depende da mídia para que o dilúvio diário completamente confuso de informações sobre riscos ambientais, tecnologias e iniciativas faça sentido. Todavia, o papel da mídia como ator social e estabelecimento de agendas é muito complexo.

Para Floriani (2004), o poder da mídia na consciência individual é marcado pela presença de novos artefatos de informação que impõem outras maneiras de comunicar e de interagir. Dessa forma, os fundamentos cognitivos são alterados a partir da matriz de aprendizado e da internalização dos signos ou códigos de reconhecimento do mundo. $\mathrm{O}$ autor acrescenta um ponto de vista sociológico, segundo o qual se revela o processo 
desencadeador de novas formas de interatividade e de comunicação social pelos mecanismos tecnológicos e organizacionais oriundos da era digital (como a TV e o computador). O papel de mediação desse ator social na formulação dos problemas e questões ambientais é particularmente preocupante no sentido de que a degradação ambiental por ele veiculada não representa uma crítica do paradigma tecnológico, mas uma simples extensão do corpo na história de degradação ambiental.

\section{Considerações Finais}

Este artigo refletiu, com ilustrações e exemplos, sobre as políticas públicas ambientais e a garantia da prestação de informações ambientais no Paraná. Alguns dos resultados a que se chegou sugerem desdobramentos, na medida em que indicam pistas para novos estudos sobre os instrumentos jurídicos e divulgação das informações ambientais. Particularmente, no que diz respeito ao percurso desta análise, interessa adicionar o seguinte conjunto de reflexões:

Há necessidade de aprimoramento da legislação ambiental e do aparelhamento dos órgãos públicos para tornar efetivo o direito à informação de meio ambiente. Neste sentido, seria oportuna uma Lei Federal e Estadual que regulamentasse o exercício do direito à informação ambiental, com prescrições sobre formas de fornecimento de informações, prazos e demais aspectos procedimentais. É preciso, também, que os dados ambientais estejam disponíveis e organizados. Para tanto, deve haver previsão quanto à padronização e à sistematização das informações, uniformização de terminologia e integração de todos os bancos de dados federais, estaduais e municipais que versem sobre recursos ambientais e qualidade do meio ambiente no Paraná.

As instituições públicas paranaenses enfrentam dois desafios simultaneamente: o de lidar com orçamentos restritos e, ao mesmo tempo, atender à demanda crescente da população. O primeiro desafio é a necessidade de maior eficiência, pois atualmente, há uma cobrança mais ampla da sociedade em relação à responsabilidade orçamentária. Porém, o fato de exigir responsabilidade nos gastos não significa que sociedade concorde abrir mão de seus direitos adquiridos. Ao contrário, a partir do governo militar, nota-se um maior amadurecimento político que reforça a cobrança da população para que o Poder Público (federal, estadual e municipal) cumpra seu papel. De fato, tanto a Constituição Federal e a Constituição Estadual do Paraná ampliaram os direitos sociais e garantia desses direitos, melhores condições que propiciem o desenvolvimento equilibrado da vida em todas as suas formas. Este constitui o segundo desafio do setor público: atender a demandas crescentes da população. 
Se a construção de uma sociedade ambientalmente responsável e democrática continua sendo um projeto, algo situado em um devir indeterminado, a mediação - a circulação de significado - das informações ambientais pela mídia e setor público deve ser melhor estudada e compreendida. É preciso, pois, ser capaz de identificar os momentos em que o processo parece falhar, em que é distorcido pela tecnologia ou propositalmente modificado - além da necessidade de compreender o desdobramento de sua política e sua vulnerabilidade ao exercício do poder público, seu próprio poder de persuadir e de reclamar atenção e resposta.

\section{Referências}

BECK, U. O que é globalização? Equívocos do globalismo. São Paulo: Paz e Terra, 1999.

BOURDIEU, P. Sobre a televisão. Rio de Janeiro: Jorge Zahar, 1997.

CONFERÊNCIA DAS NAÇÕES UNIDAS SOBRE MEIO AMBIENTE E DESENVOLVIMENTO. Agenda 21, Brasília, Senado Federal, Subsecretaria de Edições Técnicas, 1996.

CASTELlS, M. A sociedade em rede. A era da informação: economia, sociedade e cultura. São Paulo: Paz e Terra, 1999, v. 1.

FIORILLO, C. A. P. Curso de direito ambiental brasileiro. São Paulo: Saraiva, 2002.

FLORIANI, D. Conhecimento, meio ambiente e globalização. Curitiba: Juruá, 2004.

GALEANO, E. A caminho de uma sociedade da incomunicação? In: MORAES, D. Sociedade midiatizada. Rio de Janeiro: Mauad, 2006, pp. 149-154.

GONÇALVES, J. Só 4\% dos autos de infração do IAP resultaram em multa. Gazeta do Povo, Curitiba, Meio Ambiente, 16 jun. 2011, p. 6.

IANNI, O. Teorias da globalização. Rio de Janeiro: Civilização Brasileira, 2002.

KÄSSMAYER, K. Depois do codigo florestal, voltemos ao debate dos resíduos? Gazeta do Povo, Curitiba, p. 2 - 2, 05 jun. 2011.

MACHADO, P. A. L. Direito à informação e meio ambiente. São Paulo: Malheiros, 2006.

OLIVEIRA, F. M. G. Difusos e coletivos: direito ambiental. São Paulo: Editora Revista dos Tribunais, 2010, v. 15.

SILVA, F. C. T. Brasil, em direção ao século XXI. In: LINHARES, M. Y. História geral do Brasil. Rio de Janeiro: Elsevier, 1990, p. 385-445.

SILVERSTONE, R. Por que estudar a mídia? São Paulo: Edições Loyola, 2005.

THOMPSON, J. B. A mídia e a modernidade: uma teoria social da mídia. Petrópolis: Vozes, 2009. 